\section{Intravenous nifedipine for prevention of myocardial ischaemia after coronary revascularization}

Jean-Yves Dupuis MD, * Howard J. Nathan MD,* Sylvie Laganière, $\mathrm{PhD} \dagger$
We sought to determine the pharmacokinetic and pharmacodynamic behaviour of a continuous infusion of nifedipine given for prevention of myocardial ischaemia following coronary arten bypass graft (CABG) surgery. Patients scheduled for elective $C A B G$, who had good left ventricular function, were included. Only normotensive patients who did not require treatment with vasoactive drugs and were bleeding less than $100 \mathrm{ml} \cdot \mathrm{hr}^{-1}$ following surgery were included. The patients were randomly distributed into two groups: a control group not receiving any treatment and a treated group receiving a bolus $\left(3 \mu \mathrm{g} \cdot \mathrm{kg}^{-1}\right.$. $\mathrm{min}^{-1}$ for $5 \mathrm{~min}$ ) and maintenance $\left(0.2 \mu \mathrm{g} \cdot \mathrm{kg}^{-1} \cdot \mathrm{min}^{-1}\right)$ infusion of nifedipine, starting upon arrival in the recovery room and continuing for four hours. Patients given nifedipine were compared with control patients in order to determine the effects of nifedipine on haemodynamic function and on the postoperative incidence of hypotension, hypertension, myocardial ischaemio and infarction. Continuous 2-lead Holker monitoring was used

\section{Key words}

COMPLICATIONS: hypotension, hypertension;

HEART: myocardial ischaemia and infarction; PHARMACOLOGY: nifedipine;

SURGERY: cardiac.

From the Department of Anaesthesia,* University of Ottawa, Ottawa, Ontario, Canada, and Biopharmaceutics, Bureau of Drug Research, $\dagger$ Ottawa, Ontario, Canada.

Supported by grants from the P.S.I. Foundation, Ontario, Canada, and by Miles Canada, Inc.

Dr. Nathan holds a Career Scientist Award from the Ontario Ministry of Health.

Address correspondence to: Dr. H.J. Nathan, Room H460A Ottawa Civic Hospital, 1053 Carling Avenue, Ottawa, Ontario, Canada, KJY 4E9. Telephone: (613) 761-4775. Fax: (613) 729-3937.

Accepted for publication 13th August, 1992. to detect myocardial ischaemia. Infarction was diagnosed by 12 lead ECGs and by assessment of the MB-isoenzyme creatine kinase. The infusion of nifedipine rapidly achieved and mtaintained plasma concentrations between 30 and $40 \mathrm{ng} \cdot \mathrm{m} l^{-1}$. The pharmacokinetic studies revealed a systemic clearance of nifedipine of $0.371 \pm 0.101 \mathrm{~L} \cdot \mathrm{hr}^{-1} \cdot \mathrm{kg}^{-1}$, an apparent volume of distribution of $0.764 \pm 0.288 \mathrm{~L} \cdot \mathrm{kg}^{-1}$ and an elimination half-life of $1.4 \pm 0.6 \mathrm{hr}$. No correlation was found between plasma concentration of nifedipine and mean arterial pressure (MAP). The incidence of postoperative hypotension ( $M A P<70 \mathrm{mmHg}$ ) and hypertension (MAP> $100 \mathrm{mmHg}$ ) was comparable between the groups. All haemodynamic variables were similar in both groups during the study period. Of 23 patients who received nifedipine, none showed evidence of ischaemia within six hours of starting the infiusion. During the same period, five of 24 patients in the control group had ST-segment deviation suggestive of myocardial ischaemia $(P=0.05$, Fisher's exact test $)$. Three patients in the control group and none in the nifedipine group suffered perioperative myocardial infarction ( $P=N S)$. In conclusion, the continuous infusion of nifedipine used in this study is safe and reduces the incidence of myocardial ischaemia in normotensive patients with good left ventricular function following CABG. Further studies of larger number of patients are required to determine the role of caicium entry blockers following coronary artery sugery.

La présente étude a pour but de déterminer la pharmacocinétique et les effets hémodynamiques d'une perfusion intraveineuse de nifédipine administrée afin de prévenir l'ischémie myocardique après la chirurgie pour pontage aorto-coronarien (PAC). Des patients avec une bonne fonction cardiaque, admis pour une chirurgie élective participent à l'étude. Les troubles d'hémostase, l'hypertension postopératoire et l'utilisation d'agents vasoactifs sont des criteres d'exclusion. A l'arrivée à la salle de réveil, les patients sont distribués ai hasard en un groupe controle et un groupe traité avec une perfusion de nifédipine d̀ la dose de $3 \mu \mathrm{g} \cdot \mathrm{kg}^{-1} \cdot \mathrm{min}^{-1}$ pendant $5 \mathrm{~min}$ suivie de 0,2 $\mu g \cdot \mathrm{kg}^{-1} \cdot \min ^{-1}$ pendant quatre heures. Des comparaisons sont faites entre les groupes afin de déterminer les effets de la nifédipine sur les paramètres hémodynamiques, ainsi que sur 
l'incidence d'hypotension, d'hypertension, d'ischémie et d'infarctus du myocarde postopératoires. Un moniteur Holter sert à détecter l'ischémie. Des électrocardiogrammes en série et la mesure de l'enzyme créatine kinase (fraction myocardique) servent au diagnostic d'infarctus. La perfusion de nifédipine permet d'atteindre et de maintenir un niveau plasmatique de 30 à $40 \mathrm{ng} \cdot \mathrm{ml}^{-1}$. L'etude pharmacocinétique détermine une clair. ance systémique de la nifédipine à $0,371 \pm 0,10 \mathrm{I} \mathrm{L} \cdot \mathrm{h}^{-1} \cdot \mathrm{kg}^{-1}$, un volume de distribution apparent à $0,764 \pm 0,288 \mathrm{~L} \cdot \mathrm{kg}^{-1}$ et une demi-vie d'élimination à $1,4 \pm 0,6 \mathrm{hr}$. Il n'existe pas de corrélation entre la concentration plasmatique de nifédipine et la pression artérielle moyenne $(\mathrm{Pa})$. Les paramètres hémodynamiques ainsi que l'incidence d'hypotension $(\mathrm{Pa}<70 \mathrm{mmHg})$ et d'hypertension ( $\mathrm{Pa}>100 \mathrm{~mm} \mathrm{Hg}$ ) postopératoires sont comparables entre les groupes durant l'étude. Aucun des 23 patients traités avec la nifédipine inraveineuse ne présente de l'ischémie myocardique au cours des six heures qui suivent le début de la perfusion Durant le même temps, 5 des 24 patients du groupe contrôle ont des anomalies électrocardiographiques suggérant la présence d'ischémie ( $P=0,05$; test de Fisher). Le diagnostic d'infarctus postopératoire est fait chez trois patients du groupe contrôle. Aucun patient traité avec nifédipine n' a cette complication ( $P=0.23$ ). En conclusion, l'adminisration intraveineuse de nifédipine aux doses utilisées dans cette étude est sécuritaire, et peut diminuer l'incidence d'ischémie myocardique après PAC chez des patients normotendus ayant une bonne fonction cardiaque. $D$ autres études avec un plus grandéchantillon sont nécessaires afin de mieux définir le rôle des inhibiteurs de canaux calciques après la chirurgie pour PAC.

During the first six hours after coronary artery bypass graft surgery (CABG), up to $40 \%$ of patients may show evidence of myocardial ischaemia. ${ }^{1,2}$ The importance of this ischaemia and its relation to cardiac morbidity remain unclear. However, recent studies have found that of all perioperative ischaemic events, postoperative ischaemia shortly after coronary artery revascularization may be the best predictor of myocardial infarction. ${ }^{2,3}$

More than $50 \%$ of the episodes of myocardial ischaemia after CABG surgery are not correlated with increased heart rate or blood pressure. ${ }^{1,2}$ This suggests that decreased myocardial oxygen supply may cause these ischaemic episodes and that drugs having a positive effect on myocardial oxygen supply may be effective in their prevention. Nifedipine is a dihydropyridine calcium channel entry blocker which can increase myocardial oxygen supply. ${ }^{4-8}$ The intravenous infusion of nifedipine for $24 \mathrm{hr}$, beginning during surgery, was recently found to reduce the incidence of myocardial ischaemia after coronary artery surgery. ${ }^{9}$ However, the adminisration of nifedipine can also reduce blood pressure ${ }^{7,8}$ and cause myocardial depression. ${ }^{5}$ These effects could be detrimental during the critical recovery period following $C A B G$ surgery.

At present, most available pharmacokinetic and pharmacodynamic data regarding the use of nifedipine after coronary artery surgery come from studies of patients treated for postoperative hypertension. ${ }^{10,11}$ The present prospective study was undertaken in stable and normotensive patients given a prophylactic infusion of nifedipine started in the early recovery period and continued for four hours following CABG surgery. A dose regimen including a bolus and a maintenance infusion was first developed in pilot studies in order to achieve the highest plasma concentration of nifedipine without causing hypotension in most patients. This regimen was then evaluated in a controlled trial. Plasma levels of nifedipine were measured throughout the study and a correlation was made with haemodynamic variables. Patients given nifedipine were compared with control patients in order to determine the effects of nifedipine on haemodynamic function and on the postoperative incidence of hypotension, hypertension, myocardial ischaemia and infarction.

\section{Methods}

\section{Patient population}

With approval of the Human Research Ethics Committee, written informed consent was requested from all patients admitted for elective CABG surgery. Preoperative exclusion criteria were previous coronary artery surgery, poor left ventricular function (ejection fraction $<0.40$ or abnormal contraction of more than $50 \%$ of the left ventricle in the right anterior oblique projection during contrast ventriculography), myocardial infarction (MI) within three months, poorly controlled hypertension (BP > 140/90), valvular heart disease, diabetes mellitus, age greater $>70$ $\mathrm{yr}$ and the presence of ECG findings interfering with the accurate diagnosis of myocardial ischaemia (e.g., left bundle branch block (LBBB)). Postoperative exclusion criteria were excessive bleeding, new LBBB, sustained hypertension (mean arterial pressure MAP > $100 \mathrm{mmHg}$ ) and low cardiac output (cardiac index $<2.2$ $\left.\mathrm{L} \cdot \mathrm{min}^{-1} \cdot \mathrm{m}^{-2}\right)$. Only stable patients with normal blood pressure (MAP between 70 and $100 \mathrm{mmHg}$ ) after a period of stabilization ( 30 to $45 \mathrm{~min}$ ) following transfer to the cardiac recovery room (CRR) were randomized. In this selected population we could avoid the use of other pharmacological agents (vasopressors or vasodilators) which could alter coronary blood flow and myocardial oxygen demand, and confound the effect of nifedipine on the incidence of myocardial ischaemia.

Anaesthetic

All cardiac medications were continued until two hours 
before surgery. The anaesthesia technique was standardized for all patients. Premedication consisted of oral lorazepam $0.05 \mathrm{mg} \cdot \mathrm{kg}^{-1}$, intramuscular morphine 0.15 $\mathrm{mg} \cdot \mathrm{kg}^{-1}$ and scopolamine $0.006 \mathrm{mg} \cdot \mathrm{kg}^{-1}$. Anaesthesia was induced with fentanyl citrate $50 \mu \mathrm{g} \cdot \mathrm{kg}^{-1}$ and the intubation facilitated with a muscle relaxant mixture of metocurine $\left(0.016 \mathrm{mg} \cdot \mathrm{kg}^{-\mathrm{J}}\right)$ and pancuronium $(0.04$ $\left.\mathrm{mg} \cdot \mathrm{kg}^{-1}\right)$. Mechanical ventilatory support was then adjusted to maintain $\mathrm{PaCO}_{2}$ between 36 and $40 \mathrm{mmHg}$ as measured by analysis of arterial blood gas. Intraoperative hypertension was treated by deepening anaesthesia with isoflurane or by infusion of nitroglycerin before cardiopulmonary bypass (CPB). When clinically suspected, intraoperative myocardial ischaemia was treated with intravenous nitroglycerin.

Myocardial protection during the aortic cross-clamping time was accomplished with cold potassium cardioplegia (Plegisol; Abbott Laboratories, Chicago, IL), topical cooling and systemic hypothermia (30 to $32^{\circ} \mathrm{C}$ rectal temperature). A rectal temperature of $37^{\circ} \mathrm{C}$ was required in all patients before separation from CPB. No nitroglycerin was administered during or after CPB. After completion of surgery, patients were transferred to the CRR where they remained intubated with their lungs being mechanically ventilated until the following morning.

\section{Randomization and nifedipine regimen}

Following transfer to $C R R$, eligible patients were randomized into a control group or a nifedipine group. The randomization was carried out within six blocks according to the preoperative antianginal medication: nifedipine, diltiazem, beta blocker, nifedipine and beta blocker, diltiazem and beta blocker, no calcium entry blocker or beta blocker. This prestratification was done only to ensure that patients with different medication histories would be equally distributed between the groups.

The patients in the control group were managed in the same way as the nifedipine patients except that they did not receive the medication. In the nifedipine group a prophylactic infusion of nifedipine was administered for four hours in an open label manner. Nifedipine for infusion was supplied by Miles Laboratories Inc. in a concentration of $0.1 \mathrm{mg} \cdot \mathrm{ml}^{-1}$ in tinted bottles. The drug was administered into a central vein through polyethylene tubing wrapped in aluminium foil to avoid exposure of this photosensitive solution to light. One objective was to have similar haemodynamic function between the control and the treated groups so that a possible direct effect of nifedipine on the coronary vessels could be observed. Studies in pilot cases were first conducted. These allowed us to determine that a nifedipine plasma concentration of $30 \mathrm{ng} \cdot \mathrm{ml}^{-1}$ could be obtained without causing hypotension in most patients. In order to achieve and maintain a plasma concentration of $30 \mathrm{ng} \cdot \mathrm{ml}^{-1}$ rapidly, the infusion was started at a rate of $3 \mu \mathrm{g} \cdot \mathrm{kg}^{-1} \cdot \mathrm{min}^{-1}$ for five minutes, then continued at $0.2 \mu \mathrm{g} \cdot \mathrm{kg}^{-1} \cdot \mathrm{min}^{-1}$ for four hours. Whenever patients of either group had a MAP below 70 $\mathrm{mmHg}$, Ringer's lactate was infused in order to maintain pulmonary artery wedge pressure (PCWP) over $15 \mathrm{mmHg}$ and drug infusion was stopped for the nifedipine group in absence of immediate response to fluid administration. The patients in the nifedipine group who had their infusion stopped before the end of the four-hour treatment period were kept in the nifedipine group for data analysis.

Postoperative hypertension was defined as an electronically averaged mean radial arterial pressure (MAP) of $100 \mathrm{mmHg}$ or greater, sustained for ten minutes despite analgesia and sedation with intravenous morphine $(0.05$ to $\left.0.1 \mathrm{mg} \cdot \mathrm{kg}^{-1}\right)$ and diazepam $\left(0.05\right.$ to $\left.0.1 \mathrm{mg} \cdot \mathrm{kg}^{-1}\right)$. Patients who developed hypertension after initial randomization were excluded from the comparative data analysis, and were separately followed until the end of the study period. They were treated for two to four hours with intravenous nifedipine at a rate of $3 \mu \mathrm{g} \cdot \mathrm{kg}^{-1} \cdot \mathrm{min}^{-1}$ for 5 to $15 \mathrm{~min}$ and then reduced to 0.33 to $0.67 \mu \mathrm{g} \cdot \mathrm{kg}^{-1} \cdot \mathrm{min}^{-1}$ according to blood pressure response. Whenever this treatment failed, sodium nitroprusside (SNP) was added at a rate of 0.5 to $8 \mu \mathrm{g} \cdot \mathrm{kg}^{-1} \cdot \mathrm{min}^{-1}$.

\section{Pharmacokinetic analysis}

Nifedipine plasma concentration was measured immediately before infusion of the drug, then at $5,10,15,20,30$, $45,60,90,120 \mathrm{~min}$ after the initial bolus, at termination of the infusion and also 30,60 and 120 min afterwards. For each measurement of nifedipine concentration, $5 \mathrm{ml}$ of blood were collected in foil-wrapped tubes containing EDTA. Plasma was separated after centrifugation and stored frozen until analysis. Handling of samples was performed under gold fluorescent light to prevent photodegradation of nifedipine. The analytical procedure used was a modification of the method of Jakobsen et al. ${ }^{12} \mathrm{Nife}$ dipine and nitrendipine were supplied by Miles Laboratories Inc. The analysis was performed using nitrendipine as internal standard on a gas chromatograph equipped with an electron capture detector. The concentration of nifedipine in the samples was assayed in duplicate and determined from a calibration curve run daily. The calibration curves were linear in the range of 4 to $100 \mathrm{ng} \cdot \mathrm{ml}^{-1}$. The method provides precision and accuracy over the entire range of concentration with an inter-assay coefficient of variation less than $10 \%$. The detection limit is $2 \mathrm{ng} \cdot \mathrm{ml}^{-1}$. The pharmacokinetic profile of nifedipine was determined for each patient. The total systemic clearance $\left(\mathrm{Cl}_{\mathrm{s}}\right)$ was calculated as the ratio of the final infusion rate to the equilibrium concentration measured in plasma. The steady state concentration $\left(\mathrm{C}_{\mathrm{ss}}\right)$ was determined from three 
consecutive plasma levels with less than $10 \%$ variation in concentration. The elimination half-life was calculated from the slope of the semilog-linear least squares regression equation, fitted to the terminal data points (concentrations at discontinuation and after stopping the infusion). ${ }^{13}$ An apparent volume of distribution was calculated by $\mathrm{Cl}_{s} / \mathrm{t}^{-1}$ where $t$ is the terminal disposition rate constant.

\section{Haemodynamic monitoring and measurements}

Electrocardiographic (ECG) leads II and $\mathrm{V}_{5}$ were continuously monitored in the operating room. Radial arterial, peripheral venous and internal jugular vein catheters were inserted under local anaesthesia. A thermodilution pulmonary artery catheter was inserted via the internal jugular vein cannula. Heart rate, cardiac output, PCWP, systemic, central venous and pulmonary artery pressure were measured before and throughout the operative period. In both groups, those measurements were repeated on arrival in recovery room, prior to randomization, and hourly for six hours. In the nifedipine group, those measurements were also taken $5,10,15,20,30$ and $45 \mathrm{~min}$ after the beginning of treatment. Following the first six hours after randomization, heart rate, systolic, diastolic and mean arterial blood pressure were recorded hourly in both groups until the day after surgery. All episodes of hypotension (MAP $<70 \mathrm{mmHg}$ ) and hypertension during the six hours after randomization were also recorded.

Holter monitoring and electrocardiographic recordings Thirty minutes before arrival in the operating room, a Del Mar Avionics Holter 445 Monitor (Irvine, CA, USA) was applied to each patient using silver/silver chloride electrodes. Leads II and bipolar $\mathrm{V}_{5}\left(\mathrm{CS}_{5}\right)$ were monitored until $08 \mathrm{~h} 00$ the day after surgery. All Holter tapes were analysed on a Marquette series 8000T Laser Holter analyzer by two technicians blinded to the study. All abnormal QRS complexes (e.g., those with ventricular beats or LBBB) were eliminated. The ST segment baseline was determined on a 30 to $60 \mathrm{~min}$ trend average, and was repeatedly reassessed on the basis of clinical information provided with the tapes. This information included haemodynamic data, patients' movements, pre- and postoperative 12-lead ECG recordings, body temperature, serum levels of isoenzymes and electrolytes. An ischaemic episode was defined as a new transient horizontal or downsloping ST segment depression of $\geq 0.1 \mathrm{mV}$ from baseline measured at $J+80 \mathrm{msec}$, lasting for at least one minute and separated from other episodes by at least one minute. ${ }^{14}$ New ST segment elevations were classified as ischaemic episodes when the $\mathrm{J}$ point was $\geq 2 \mathrm{mV}$ over the baseline for at least one minute. ${ }^{15}$

The number of episodes of ST segment deviations from baseline were counted for each patient. For each episode, the point of maximum ST segment change was reported and the duration was measured from the point where the ST segment began to shift from baseline until it returned to baseline. The area under the ST segment deviation trend curve (time-deviation AUC) was also calculated by the Holter analyzer according to a previously described method. ${ }^{16}$ This measurement represents the integral of all ST segment deviation for the duration of the episode. When an ischaemic episode was present on both Holter channels at the same time, it was computerized as a single episode with the highest values for duration, peak ST changes and time-deviation AUC being entered in the study. Ischaemic episodes were considered to be related to haemodynamic abnormality when they were accompanied by a heart rate higher than $90 \mathrm{bpm}$ or a $20 \%$ increase from basal heart rate, or a bradycardia $(<50 \mathrm{bpm})$, or MAP > $100 \mathrm{mmHg}$, or MAP $<60 \mathrm{mmHg}$.

Comparisons of Holter monitoring between the groups were made at four different times during the perioperative course: (1) during the prebypass period; (2) during the surgical postbypass period which included the time between coming off CPB and randomization; (3) the first six hours following randomization which represented the drug evaluation period; (4) the post-drug evaluation period which lasted 12 to $14 \mathrm{hr}$. The drug evaluation period was meant to test the effectiveness of nifedipine in the prevention of myocardial ischaemia and a six-hour period was selected in consideration of the duration of the nifedipine infusion (four hours), its calculated half-life (see results) and an arbitrarily selected minimal effective concentration of $10 \mathrm{ng} \cdot \mathrm{ml}^{-1}$.

The day before surgery, all patients had 12-lead ECG recordings. Those were repeated two hours after arrival to CRR, then on the first, second and fifth or sixth postoperative days. All ECG tracings were read by cardiologists working in the ECG laboratory. The tracings which showed postoperative changes were reviewed by a single cardiologist unaware of the patients' treatment. The diagnosis of MI was made when a significant new $Q$ wave was present, or when ECG changes like LBBB or poor Rwave progression in the anterior leads were accompanied by an elevation of the MB-isoenzyme of creatine kinase (MB-CK) over 60 IU.

\section{Biochemical analysis}

The CK, MB-CK isoenzyme, lactate dehydrogenase and serum aspartate aminotransferase (AST) levels were assessed two hours after surgery, then on the first and second postoperative days.

\section{Data analysis}

Data are given as mean values \pm standard deviation (SD). 
Student's unpaired t test was used for parametric analysis of the quantitative data. For variables like sex distribution, number of patients with history of hypertension, previous MI, left main coronary artery stenosis, internal mammary artery grafts and the incidence of myocardial ischaemia or infarction, comparisons were made using the two-tailed Fisher's exact probability tests. The Chi-square test was used for the analysis of all other categorical data with correction for continuity when appropriate. Correlations between nifedipine plasma concentration and haemodynamic variables were made using simple linear regression. Haemodynamic data were compared by analysis of variance for repeated measures, using Dunnett's t test to compare the baseline values with subsequent values within a group and using multiple $t$ tests with Bonferroni correction for comparisons between the groups at different times. $P<0.05$ was considered to be statistically significant.

\section{Results}

Sixty-three patients met the inclusion criteria and were randomized to a control group $(n=32)$ and a nifedipine group ( $n=31$ ). Both groups had comparable preoperative and operative characteristics (Tables I and II). Six control and seven patients treated with nifedipine developed hypertension during the study period and were followed separately from the other patients until the end of the study.

The 24 patients who remained normotensive in the nifedipine group received an average of $3.8 \pm 1.3 \mathrm{mg}$ of nifedipine (range: $0.9-5.7 \mathrm{mg}$ ) during the study period. Plasma levels of nifedipine were determined in 20 of these patients and in five of the seven nifedipine patients who became hypertensive during the study. The nifedipine $\mathrm{C}_{\mathrm{ss}}$ could not be determined in the patients who had their infusion stopped early during the study and in those who needed an anti-hypertensive drug regimen. The nifedipine $\mathrm{C}_{\mathrm{ss}}$ was determined in 18 patients who remained normotensive throughout the study and its value was 36.2 $\pm 12.3 \mathrm{ng} \cdot \mathrm{ml}^{-1}$. The plasma concentrations of nifedinine over time for these 18 patients are shown in Figure 1. The following variables were evaluated from plasma concentration data obtained at steady state: $\mathrm{Cl}_{\mathrm{s}}=0.371 \pm 0.101$ $\mathrm{L} \cdot \mathrm{h}^{-1} \cdot \mathrm{kg}^{-1}$, apparent volume of distribution $=0.764 \pm$ $0.288 \mathrm{~L} \cdot \mathrm{kg}^{-1}$, elimination half-life $=1.4 \pm 0.6 \mathrm{hr}$.

The effect of the rapid increase in nifedipine plasma concentration on haemodynamic function was studied by comparing baseline values with those obtained at the end of the bolus infusion (Table III). The acute administration of the drug produced a significant fall in MAP and SVR with minimal effect on $\mathrm{HR}$ and $\mathrm{CI}$. No correlation was found between the nifedipine plasma concentration and the percent changes in MAP or SVR associated with the bolus infusion of nifedipine. Similarly, during the entire drug
TABLE I Preoperative characteristics of the patients

\begin{tabular}{lll}
\hline & Control & Nifedipine \\
\hline No. of patients & 32 & 31 \\
Female & $3(9)$ & $4(13)$ \\
Male & $29(91)$ & $27(87)$ \\
Age (years) & $55 \pm 8$ & $54 \pm 9$ \\
Weight (kg) & $78.9 \pm 13.8$ & $80.3 \pm 16.6$ \\
History of hypertension & $11(34)$ & $13(42)$ \\
Prior MI & $19(59)$ & $21(68)$ \\
CCS angina class: & & \\
-1 & $6(8)$ & $1(4)$ \\
-2 & $16(50)$ & $14(44)$ \\
-3 & $12(38)$ & $16(52)$ \\
- & $1(4)$ & $0(0)$ \\
Antianginal therapy & & \\
- Nifedipine & $0(0)$ & $1(3)$ \\
- Diltiazem & $7(22)$ & $10(32)$ \\
- BB & $7(22)$ & $5(16)$ \\
- Nifedipine + BB & $4(12)$ & $1(3)$ \\
- Diltiazem + BB & $10(32)$ & $10(32)$ \\
- No CEB or BB & $4(12)$ & $4(13)$ \\
Diseased vessels : & & \\
- 1 & $4(13)$ & $0(0)$ \\
- 2 & $9(28)$ & $8(26)$ \\
- 3 & $18(56)$ & $20(65)$ \\
- 4 & $1(3)$ & $3(9)$ \\
Left main stenosis & $6(19)$ & $6(19)$ \\
\hline
\end{tabular}

Mean \pm S.D. Numbers in parentheses are percentages. $M I=$ myocardial infarction; CCS = Canadian Cardiovascular Society; $\mathrm{CEB}=$ calcium entry blocker. $\mathrm{BB}=$ beta blocker. No significant differences were found between the groups.

TABLE II Operative data analysis

\begin{tabular}{lll}
\hline & $\begin{array}{l}\text { Control } \\
(n=32)\end{array}$ & $\begin{array}{l}\text { Nifedipine } \\
(n=31)\end{array}$ \\
\hline X-clamp time (min) & $45 \pm 15$ & $40 \pm 15$ \\
CPB duration (min) & $88 \pm 25$ & $83 \pm 27$ \\
No. of grafts/patient & $3 \pm 1$ & $3 \pm 1$ \\
- One graft/patients & $0(0)$ & $1(3)$ \\
- Two grafts/patient & $8(25)$ & $6(19)$ \\
- Three grafts/patient & $14(44)$ & $15(49)$ \\
- Four grafts/patient & $8(25)$ & $9(29)$ \\
- Five grats/patient & $2(6)$ & $0(0)$ \\
Patients with IMA grafts & $26(81)$ & $21(68)$ \\
Pre-CPB duration (min) & $117 \pm 20$ & $114 \pm 24$ \\
Pre-CPB isoflurane & $11(34)$ & $10(32)$ \\
Pre-CPB nitroglycerin & $17(53)$ & $15(48)$ \\
Pre-CPB ischaemia & $3(9)$ & $3(10)$ \\
Elapsed time between end of CPB & & \\
$\quad$ and randomization (min) & $64 \pm 15$ & $64 \pm 17$ \\
Post-CPB isoflurane & $7(22)$ & $7(23)$ \\
Post-CPB nitroglycerin & $0(0)$ & $0(0)$ \\
Ischaemia between end of CPB & & $2(6)$ \\
and randomization & $2(6)$ & \\
\hline
\end{tabular}

Mean \pm SD. Numbers in parentheses are percentages. $X$-clamp $=$ aortic cross-clamp; $\mathrm{CPB}=$ cardiopulmonary bypass; IMA = intemal mammary artery. No significant diffenences were found between the groups. 


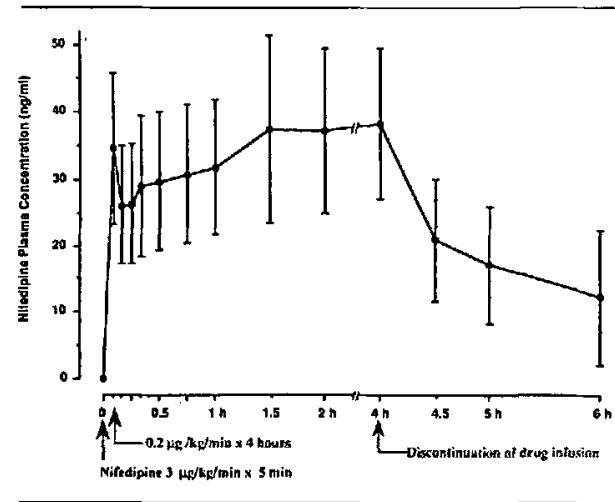

FIGURE 1 Plasma concentrations of nifedipine during the drug evaluation period. A loading dose of $3 \mu \mathrm{g} \cdot \mathrm{kg}^{-1} \cdot \mathrm{min}^{-1}$ for five minutes followed by a four-hour infusion of $0.2 \mu \mathrm{g} \cdot \mathrm{kg}^{-1} \cdot \mathrm{min}^{-1}$ was given. Mean $\pm \mathrm{SD}, n=18$.

TABLE $\mathrm{m}$ Alterations in hearn rate, mean arterial pressure, cardiac index and systemic vascular resistance following the rapid intravenous infusion of nifedipine ( $3 \mu \mathrm{g} \cdot \mathrm{kg}^{-1}-\mathrm{min}^{-1}$ for 5 minutes) to patients recovering from coronary artery revascularization surgery.

\begin{tabular}{|c|c|c|}
\hline Hemodynamics & $\begin{array}{l}\text { Baseline } \\
\text { vatues }\end{array}$ & $\begin{array}{l}\text { After nifedipine } \\
3 \mu g \cdot \mathrm{kg}^{-1} \cdot \mathrm{min}^{-1} \\
\text { for } 5 \mathrm{~min}\end{array}$ \\
\hline Heart rate (beatshinin) & $68 \pm 14$ & $70 \pm 14$ \\
\hline $\begin{array}{l}\text { Mean arterial pressure } \\
(\mathrm{mmHg})\end{array}$ & $87 \pm 6$ & $79 \pm 7^{*}$ \\
\hline Cardiac index $\left(L \cdot \min ^{-1} \cdot \mathrm{m}^{-2}\right)$ & $2.2 \pm 0.5$ & $2.3 \pm 0.4$ \\
\hline $\begin{array}{l}\text { Systemic vascular resistance } \\
\text { (dynes } \cdot \mathrm{sec}^{-1} \cdot \mathrm{cm}^{-5} \text { ) }\end{array}$ & $1599 \pm 426$ & $1283 \pm 346 \dagger$ \\
\hline
\end{tabular}

Mean $\pm \mathrm{SD} .{ }^{*} P=0.001 ; \uparrow P=0.004$.

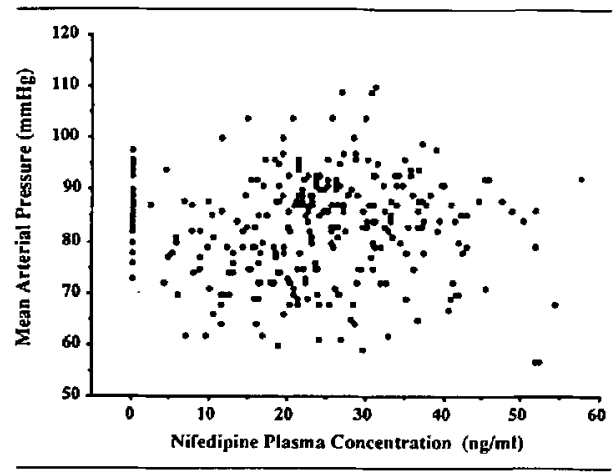

FIGURE 2 There is no correlation between the plasma concentration of nifedipine and the mean arterial pressure during the entire drug evaluation period $(n=298)$.
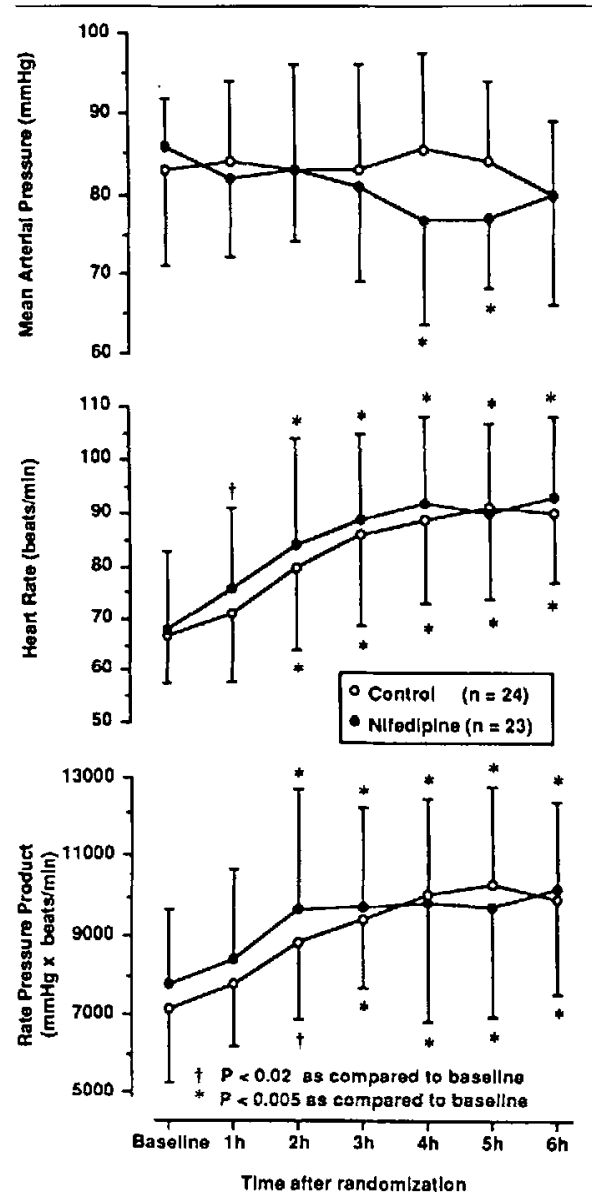

FIGURE 3 Comparison of mean arterial pressure, heart rate and rate-pressure (systolic) product between control patients and patients given a prophylactic infusion of nifedipine after coronary artery surgery. Patients who remained nomotensive and had interpretable Holter recordings are included. Mean \pm SD

evaluation period (bolus and maintenance infusion), no correlation was found between the nifedipine plasma concentration and MAP (Figure 2), SVR, CI or HR.

Control and nifedipine patients had comparable haemodynamic variables during the entire study. Values of MAP, HR and rate-pressure product (RPP) for the normotensive patients with interpretable Holter tapes during the drug evaluation period are shown in Figure 3. The HR and RPP increased significantly in both groups during the drug 
evaluation period, but at no time was there any significant difference between the groups. The MAP values within the nifedipine group were lower than baseline value $(P<0.05)$ four and five hours after randomization. However, there was no significant difference of MAP between the groups at any time. Nine patients in the control group versus ten in the nifedipine group had one or more episodes of hypotension (MAP $<70 \mathrm{mmHg}$ ) during the drug evaluation period. Dopamine $\left(5 \mu \mathrm{g} \cdot \mathrm{kg}^{-1} \cdot \mathrm{min}^{-1}\right)$ was required to normalize the blood pressure in one control patient. In all the others, the blood pressure increased with fluid administration, and cessation of drug infusion in the nifedipine group when judged necessary. Three patients in the nifedipine group had their nifedipine infusion stopped during the first hour, one during the third hour and three during the fourth hour because their MAP was $<70 \mathrm{mmHg}$ despite fluid administration. Low SVR $<900$ dynes. $\mathrm{sec}^{-1} \cdot \mathrm{cm}^{-5}$ ) was the cause of hypotension in four control patients and four of the nifedipine patients who had their infusions stopped. A combination of factors ( $\mathrm{CI}$ between 1.8 and $2 \mathrm{~L} \cdot \mathrm{min}^{-1} \cdot \mathrm{m}^{-2}$ with low filling pressure) explained the low MAP in the others.

During the four-hour drug infusion period, systemic vascular resistance (SVR) decreased from $1557 \pm 343$ (baseline value) to $1370 \pm 409$ dynes $\cdot \mathrm{sec}^{-1} \cdot \mathrm{cm}^{-5}$ in the control group versus $1614 \pm 368$ (pre-drug value) to 1147 \pm 285 dynes $\cdot \mathrm{sec}^{-1} \cdot \mathrm{cm}^{-5}$ in the nifedipine group. Although SVR tended to be lower in the nifedipine group, the difference never reached statistical significance. Cardiac index increased from $2.1 \pm 0.4$ at baseline to 2.5 $\pm 0.6 \mathrm{~L} \cdot \mathrm{min}^{-1} \cdot \mathrm{m}^{-2}(P<0.05)$ in the control group during the same period and this was comparable at all times with the increase from $2.1 \pm 0.4$ at baseline to $2.7 \pm 0.6$ $\mathrm{L} \cdot \mathrm{min}^{-1} \cdot \mathrm{m}^{-2}(P<0.05)$ in the nifedipine group.

Two control (the patient who needed dopamine was one of them) and one nifedipine patient had uninterpretable Holter tapes. Therefore, comparisons of the incidence of myocardial ischaemia among those who remained normotensive were made between 24 control patients and 23 patients given a prophylactic infusion of nifedipine. A complete ischaemic profile (number of episodes, peak ST segment deviation, total duration and time-deviation AUC) of each patient who had ischaemia during the four perioperative periods is shown in Table IV. Five control patients $(21 \%)$ versus none in the nifedipine group had ECG evidence of myocardial ischaemia during the drug evaluation period $(P=0.05)$. The incidence of myocardial ischaemia in each group was not significantly different during the other three perioperative periods (prebypass, surgical postbypass, and the $12-14 \mathrm{hr}$ post-drug evaluation period). There were a total of 11 ischaemic episodes in the control group during the drug evaluation period, five $(45 \%)$ of which were related to increased heart rate and six
(55\%) unrelated to any haemodynamic abnormality. The episodes during this period lasted 2 to $60 \mathrm{~min}$ with a mean duration of $12.2 \pm 19 \mathrm{~min}$ and a mean deviation-time AUC of $30.1 \pm 33.9 \mathrm{~mm} \cdot \mathrm{min}$. Myocardial ischaemia was not identified in real time in any of the patients and nitroglycerin was not given to anyone after transfer to CRR.

The six control and seven nifedipine patients who became hypertensive after randomization were treated with intravenous nifedipine. One control and three nifedipine patients required SNP as well to have their blood pressure controlled. One hypertensive patient initially randomized to the control group had a first episode of myocardial ischaemia ( $2.9 \mathrm{~mm}$ peak ST segment elevation; duration of $45 \mathrm{~min}$ ) before being hypertensive and a second episode two hours later (2.8 mm peak ST segment depression; duration of $67 \mathrm{~min}$ ) during treatment with nifedipine alone. One of the patients from the nifedipine group who needed SNP and nifedipine for treatment of postoperative hypertension had one episode of myocardial ischaemia ( $1.2 \mathrm{~mm}$ peak ST segment depression; duration of five minutes) one hour after cessation of the nifedipine infusion. An analysis of the incidence of myocardial ischaemia on the basis of intention to treat, that is including the patients who developed hypertension after randomization, shows that six of $30(20 \%)$ control patients had myocardial ischaemia during the drug evaluation period versus 1 of $30(3 \%)$ in the nifedipine group ( $P=$ NS).

Three patients in the control group and none in the nifedipine group had perioperative MI $(P=N S)$. Two of these patients had ECG (one inferior and one anterior wall) and enzymatic evidence of MI two hours after completion of surgery. The patient with inferior wall MI had Holter ECG evidence of MI before randomization, while the patient with anterior wall MI never showed abnormal Holter tracing. The third patient developed an extensive anterolateral MI $12 \mathrm{hr}$ after surgery and died of cardiogenic shock. This patient had six postoperative episodes of myocardial ischaemia, half of them during the drug evaluation period, lasting a total of $54 \mathrm{~min}$, before his MI. There was no other perioperative death.

\section{Discussion}

The nifedipine intravenous dose regimen described in this study caused no severe haemodynamic changes in a group of stable and normotensive patients following CABG surgery. The prophylactic administration of intravenous nifedipine did not reduce the incidence of postoperative hypertension, but it was accompanied by a decreased incidence of myocardial ischaemia as detected by Holter monitoring in the early postoperative period. However, the incidence of MI in this population was too low to demonstrate any effect of nifedipine on the prevention of MI. 
TABLE IV Ischaemic profile of the randomized patients with interpretable Holter tapes and myocardial ischaemia during any of the 4 perioperative periods. Only the patients who remained nomotensive during the drug evaluation period are presented

\begin{tabular}{|c|c|c|c|c|}
\hline & Pre-CBP & Post-CPB & $\begin{array}{l}\text { Drug evaluation } \\
(6 \mathrm{hr})\end{array}$ & $\begin{array}{l}\text { Post-drug } \\
(12-14 \mathrm{hr})\end{array}$ \\
\hline \multicolumn{5}{|c|}{ Control $(n=24)$} \\
\hline 1 & $\begin{array}{l}1 \text { episode }(0) \\
30 \text { minutes } \\
\text { Peak ST: }+3 \mathrm{~mm} \\
\text { AUC: } 75 \mathrm{~min}-\mathrm{mm}\end{array}$ & - & - & - \\
\hline 2 & $\begin{array}{l}1 \text { episade (1) } \\
10 \text { minutes } \\
\text { Peak ST: }+2 \mathrm{~mm} \\
\text { AUC: } 8.5 \mathrm{~min}-\mathrm{mm}\end{array}$ & $\begin{array}{l}1 \text { episode }(0) \\
13 \text { minutes } \\
\text { Peak } S T:+2 \mathrm{~mm} \\
\text { AUC: } 10 \mathrm{~min}-\mathrm{mm}\end{array}$ & $\begin{array}{l}1 \text { episode }(0) \\
2 \text { minutes } \\
\text { Peak ST: }-1.8 \mathrm{~mm} \\
\text { AUC: } 2 \mathrm{~min}-\mathrm{mm}\end{array}$ & $\begin{array}{l}3 \text { episodes ( } 3 \text { ) } \\
20 \text { minutes } \\
\text { Peak ST: }-1.9 \mathrm{~mm} \\
\text { AUC : } 24 \mathrm{~min}-\mathrm{mm}\end{array}$ \\
\hline 3 & - & - & $\begin{array}{l}3 \text { episodes }(0) \\
8 \text { minutes } \\
\text { Peak ST: }+3.3 \mathrm{~mm} \\
\text { AUC: } 18 \mathrm{~min}-\mathrm{mm}\end{array}$ & - \\
\hline 4 & - & - & $\begin{array}{l}1 \text { episode (1) } \\
60 \text { minutes } \\
\text { Peak ST: }-1.9 \mathrm{~mm} \\
\text { AUC: } 80 \mathrm{~min}-\mathrm{mm}\end{array}$ & $\begin{array}{l}6 \text { episodes (6) } \\
113 \text { minutes } \\
\text { Peak ST: }-3.6 \mathrm{~mm} \\
\text { AUC : } 148 \mathrm{~min}-\mathrm{mm}\end{array}$ \\
\hline $5^{*}$ & - & $\begin{array}{l}1 \text { episode }(0) \\
3 \text { minutes } \\
\text { Peak ST: }-1.2 \mathrm{~mm} \\
\text { ALC: } 3 \mathrm{~min}-\mathrm{mm}\end{array}$ & $\begin{array}{l}3 \text { episodes ( } 2 \text { ) } \\
8 \text { minutes } \\
\text { Peak ST: }-2.7 \mathrm{~mm} \\
\text { AUC: } 15 \mathrm{~min}-\mathrm{mm}\end{array}$ & $\begin{array}{l}3 \text { episodes (2) } \\
45 \text { minutes } \\
\text { Peak ST: }-2.5 \mathrm{~mm} \\
\text { AUC: } 76 \mathrm{~min}-\mathrm{mm}\end{array}$ \\
\hline 6 & - & - & $\begin{array}{l}4 \text { episodes (2) } \\
59 \text { minutes } \\
\text { Peak ST: }-2.3 \mathrm{~mm} \\
\text { AUC: } 71 \mathrm{~min}-\mathrm{mm}\end{array}$ & - \\
\hline \multicolumn{5}{|c|}{ Nifedipine ( $n=23$ ) } \\
\hline 1 & $\begin{array}{l}2 \text { episodes (1) } \\
31 \text { minutes } \\
\text { Peak ST: }-2.7 \mathrm{~mm} \\
\text { AUC: } 43 \mathrm{~min}-\mathrm{mm}\end{array}$ & $\begin{array}{l}3 \text { episodes }(0) \\
51 \text { minutes } \\
\text { Peak ST: }-1.7 \mathrm{~mm} \\
\text { AUC: } 149 \mathrm{~min}-\mathrm{mm}\end{array}$ & - & $\begin{array}{l}2 \text { episodes }(0) \\
13 \text { minutes } \\
\text { Peak ST: }-1.7 \mathrm{~mm} \\
\text { AUC: } 16 \mathrm{~min}-\mathrm{mm}\end{array}$ \\
\hline 2 & $\begin{array}{l}1 \text { episode }(0) \\
4 \text { minutes } \\
\text { Peak ST: }-1.2 \mathrm{~mm} \\
\text { AUC: } 4 \mathrm{~min}-\mathrm{mm}\end{array}$ & - & - & - \\
\hline 3 & - & $\begin{array}{l}1 \text { episode }(0) \\
12 \text { minutes } \\
\text { Peak ST: }+2.1 \mathrm{~mm} \\
\text { AUC: } 18.5 \mathrm{~min}-\mathrm{mm}\end{array}$ & - & - \\
\hline
\end{tabular}

Numbers in parentheses represent the number of ischaemic episodes related to increased heart rates. The total duration of all episodes during a period are expressed in minutes. AUC = total time-deviation area under the curve of all ischaemic episodes. Peak ST is the maximal ST segment deviation recorded during the period.

*Patient who had a postoperative MI and died.

\section{Pharmacokinetics}

The pharmacokinetic profile of nifedipine observed in this population of patients is comparable to that found in healthy subjects. ${ }^{17}$ All patients had a rapid infusion of nifedipine which gave peak plasma concentrations within five minutes, and this was followed by maintenance infusion of $12 \mu \mathrm{g} \cdot \mathrm{kg}^{-1} \cdot \mathrm{h}^{-1}$ which maintained plasma concentration at $30 \mathrm{ng} \cdot \mathrm{ml}^{-1}$. This rapid attainment and maintenance of drug concentration was predictable and consistent in most patients. If the main reason to use nifedipine after CABG surgery is to decrease the incidence of myocardial ischaemic events, an important objective would be to obtain a minimal anti-ischaemic concentration of the drug as soon as possible after surgery. However, the minimal anti-ischaemic plasma concentration of nifedipine is variable among the population with coronary artery disease. ${ }^{18}$ In our study, $10 \mathrm{ng} \cdot \mathrm{ml}^{-1}$ was accepted as a minimal concentration to prevent ischaemia only because other investigators had used this value as a minimum therapeutic level. ${ }^{9}$ However, further studies will be needed 
to confirm that such concentration is in fact the minimal plasma level necessary to prevent myocardial ischaemia after CABG surgery.

\section{Pharmacodynamics}

The decrease in afterload ${ }^{7,8}$ and myocardial contractility ${ }^{5}$ associated with the use of nifedipine may be an important concern in patients who have myocardial dysfunction secondary to the ischaemia-reperfusion injury which follows myocardial revascularization. ${ }^{19}$ However, the plasma levels of nifedipine seached in this study (15 to 60 $\mathrm{ng} \cdot \mathrm{ml}^{-1}$ ) were not associated with severe hypotension. None of the patients given nifedipine required inotropic support while one control patient needed dopamine to maintain an adequate blood pressure. Nifedipine was stopped before the end of the four-hour infusion in seven patients with MAP lower than $70 \mathrm{mmHg}$. This was not done because the pressure was falling rapidly, but because of our limited experience with the intravenous use of this drug and also to comply with the protocol approved by our hospital Ethics Committee. The blood pressure recovered to control group levels within one elimination half-life. Patients with MAP below $70 \mathrm{mmHg}$ did not have unusually high nifedipine plasma levels. The number of patients with episodes of mild hypotension (MAP $<70 \mathrm{mmHg}$ ) during the drug evaluation period was comparable between the groups: ten nifedipine versus nine control patients. This suggests that the bouts of hypotension were not necessarily due to nifedipine and that the drug can be given safely to these patients. This is in agreement with the findings of Seitelberger et al. ${ }^{9,10}$ who used a $24 \mathrm{hr}$ infusion of nifedipine after surgery and did not find an increased incidence of hypotension in their patients. However, the value and safety of intravenous nifedipine in the presence of severe postoperative ventricular dysfunction remains to be established.

The incidence of postoperative hypertension was similar in both groups: seven nifedipine (23\%) versus six control patients (19\%). This indicates that the low dose of nifedipine used in this study does not prevent postoperative hypertension. In fact the plasma levels of nifedipine obtained in this study $\left(C_{\mathrm{ss}}=36.2 \mathrm{ng} \cdot \mathrm{ml}^{-1}\right)$ are three to four times lower than those required to control acute hypertension after CABG surgery. ${ }^{10}$

\section{Myocardial ischaemia prevention}

The number of patients having ischaemic episodes was similar between the treatment and control group except during and immediately after nifedipine administration. The patients' preoperative and operative characteristics, and their postoperative management were similar in all other respects. This suggests that the nifedipine infusion was effective in reducing the incidence of myocardial ischaemia.
The diagnosis of myocardial ischaemia was based on the analysis of ST segment deviations recorded on a twochannel Holter monitor. While practical and easy to use for detection of silent ischaemia in ambulatory patients, this mode of monitoring is associated with difficulties in the interpretation of ST segment changes. ${ }^{21}$ This is especially true during the perioperative period where factors such as temperature changes, electrode displacement and myocardial infarction may cause a drift of the baseline and interfere with the analysis. The stringent ECG diagnostic criteria of ischaemia used in this study may have decreased the sensitivity of this monitoring technique. ${ }^{22}$ This could partly explain why the incidence of ischaemia in the control group (21\%) is lower than the $40 \%$ incidence previously reported. ${ }^{1,2}$

The pathogenesis of myocardial ischaemia after CABG surgery is most probably multifactorial and different from one patient to the other. Factors that have been implicated include: vasospasm, ${ }^{23}$ inadequate or obstructed grafts, low perfusion pressure, endothelial cell damage with decreased microcirculatory flow (no reflow phenomenon), ${ }^{24}$ increased metabolism upon recovery from anesthesia, ${ }^{25}$ increased sympathetic activity, ${ }^{26.27}$ and impaired parasympathetic activity. ${ }^{28.29}$ The variety of factors interfering with the myocardial oxygen supply/demand ratio suggests that no single intervention will prevent postoperative ischaemia in all circumstances. In this study, the anti-ischaemic effect of nifedipine was most probably related to better oxygen supply as the RPP, an index of myocardial oxygen demand, was comparable between the control and nifedipine groups throughout the drug evaluation period.

In a first study by Seitelberger et al. ${ }^{20}$ the prophylactic infusion of nifedipine after CABG surgery did not decrease the incidence of myocardjal ischaemia. This can probably be explained by some differences between their study protocol and ours. First, that study was not limited to normotensive patients. Hypertensive patients were treated by increasing the dose of the study drugs. Second, a prophylactic infusion of nitroglycerin $\left(1 \mu \mathrm{g} \cdot \mathrm{kg}^{-1}\right.$. min $^{-1}$ ) was given to all the control patients. The antiischaemic effectiveness of nitroglycerin after CABG surgery has never been demonstrated. But it is possible that nitroglycerin reduced the incidence of myocardial ischaemia in those patients, therefore attenuating the differences with the nifedipine group. Third, that study period was much longer with a 22-hr infusion of nifedipine started two hours after the aortic cross-clamp release. The present study focused on the first six hours after surgery as the peak incidence of myocardial ischaemia occurs during this early recovery period. ${ }^{1,2}$

Interestingly, in a subsequent study with a larger sample size, Seitelberger et al. ${ }^{9}$ started the administration of nifedipine or nitroglycerin before cardiopulmonary bypass (CPB), and found that the incidence of postoperative 
ischaemia was lower in the patients given nifedipine. They explained the different results between their studies by a possible beneficial effect of nifedipine during the early reperfusion period. But the difference between the two studies of Seitelberger $e t$ al. may be due to higher plasma levels of nifedipine during the early recovery period of the patients who had their infusion started before CPB. This is possible as no loading dose was given in both of their studies, and plasma concentration was not determined until $12 \mathrm{hr}$ after the beginning of the infusion.

\section{Perioperative myocardial infarction}

A therapy which could decrease the incidence of perioperative Ml could have an important impact on the late survival of patients undergoing CABG surgery. ${ }^{30}$ In the present study, nifedipine did not decrease the incidence of perioperative MI: no nifedipine versus three control patients had an MI $(P=N S)$, and one of these patients had his MI before randomization (as detected by Holter monitor). These results compare with those observed by Seitelberger et al. ${ }^{9,20}$ In both of their studies Seitelberger et al. concluded that the perioperative administration of nifedipine was associated with a lower incidence of perioperative MI as compared to the use of nitroglycerin. However, reanalysis of the data from both studies fails to support these conclusions. ${ }^{*}$ There seems to be a trend for lower perioperative MI rate with the use of nifedipine, but larger scale trials would be necessary to confirm this.

\section{Conclusion}

The present study describes a protocol of administration of intravenous nifedipine in normotensive patients with good left ventricular function following CABG surgery. The suggested dose regimen rapidly achieves a predictable plasma concentration of 30 to $40 \mathrm{ng} \cdot \mathrm{ml}^{-1}$ without alterations of haemodynamics. The prophylactic infusion of nifedipine decreased the incidence of myocardial ischae$\mathrm{mia}$ in the early postoperative period of this population. However, the small sample size and the low complication rate observed in this study did not allow us to correlate this beneficial effect with a lower infarction rate, better ventricular function or improved survival. Studies of patients at high risk of MI are needed to determine if a continuous infusion of nifedipine can reduce morbidity and mortality following CABG surgery.

\section{Acknowledgements}

The authors thank Joanne Sweet RN, Marlene Farrell RN, Maureen Burns RN, and Denise Wozny for their assistance throughout this study.

*Nathan $H$. Nifedipine after coronary bypass grafting (letter). Ann Thorac Surg 1991; 51: 693.

\section{References}

1 Knight AA, Hollenberg $M$, London MJ, et al., and the S.P.I. Research Group. Perioperative myocardial ischaemia: importance of preoperative ischaemic pattern. Anesthesiology 1988; 68: 681-8.

2 Smith RC, Leung JM, Mangano DT, and the SPI Research Group. Postoperative myocardial ischaemia in patients undergoing coronary artery bypass graft surgery. Anesthesiology 1991; 74: 464-73.

3 Leung $J M, O^{\prime}$ Kelly $B$, Browner WS, et al. Prognostic importance of postbypass regional wall-motion abnormalities in patients undergoing coronary artery bypass graft surgery. Anesthesiology 1989; 71: 16-25.

4 Specchia G, De Servi S, Falcone C, et al. Effects of nifedipine on coronary haemodynamic findings during exercise in patients with stable exertional angina. Circulation 1983: 68: 1035-43.

5 Terris S, Bourdillon PD. Cheng DT, Pitt B. Direct cardiac and peripheral vascular effects of intracoronary and intravenous nifedipine. Am J Cardiol 1986; 58: 25-30.

6 Gunther S, Green L, Muller JE, Mudge GH, Grossman W. Prevention by nifedipine of abnormal vasoconstriction in patients with coronary artery disease. Circulation 1981; 63: 849-55.

7 Gerstenblith G, Ouyang $P$, Achuff SC, et al. Nifedipine in unstable angina. A double-blind, randomized trial. N Engl J Med 1982; 306: 885-9.

8 Emanuelson $H$, Holmberg $S$. Mechanisms of angina relief after nifedipine: a haemodynamic and myocardial metabolic study. Circulation 1983; 68: 124-30.

9 Seitelberger $R$, Zwölfer W, Huber S, et al. Nifedipine reduces the incidence of myocardial infarction and transient ischaemia in patients undergoing coronary bypass grafting. Circulation 1991; 83: 460-8.

10 Nathan $H J$, Harrison $L$, Dubé $L$, et al. Intravenous nifedipine to treat hypertension following coronary artery revascularization surgery. A comparison with sodium nitroprusside. Anesth Analg 1992; 74: 809-17.

11 Davis $M E$, Jones $C J H$, Feneck $R O$, Walesby $R K$. Intravenous nifedipine for control of hypertension in patients after coronary artery bypass graft surgery. J Cardiovase Thorac Anesth 1988; 2: 130-9.

12 Jakobsen P, Lederballe Pederson O, Mikkelsen E. Gas chromatographic determination of nifedipine and one of its metabolites using electron capture detection. J Chromatogr 1979; 162: 81-7.

13 Gibaldi $M$, Perrier $D$. Pharmacokinetics. New York: Marcel Dekker, 1982.

14 Schlant RC, Blomqvist CG, Brandenburg RO, et al. Guidelines for exercise testing: a report of the American College of Cardiology/American Heart Association Task Force on assessment of cardiovascular procedures (Subcommittee on Exercise Testing). J Am Coll Cardiol 1986; 8: 725-38. 
15 Cohen $M$, Scharpf SJ, Rentrop KP. Prospective analysis of electrocardiographic variables as markers for extent and location of acute wall motion abnormalities observed during coronary angioplasty in human subjects. J Am Coll Cardiol 1987; 10: 17-24.

16 Knight AA, Hollenberg $M$, London MJ, Mangano DT, and the S.P.I. Research Group. Myocardial ischaemia in patients awaiting coronary artery bypass grafting. Am Heart J 1989; 117: 1189-95.

17 Kleinbloesem $C H$, van Brummelen $P$, van de Linde $J A$, Voogd PJ, Breimer DD. Nifedipine: kinetics and dynamics in healthy subjects. Clin Pharmacol Ther 1984; 35: 742-9.

18 Kleinbloesem $C H$, van Brummelen $P$, Breimer DD Nifedipine, relationship between pharmacokinetics and pharmacodynamics. Clin Pharmacokinet 1987; 12: 12-29.

19 Breisblatt WM, Stein $K L$, Wolfe CJ, et al. Acute myocardial dysfunction and recovery: A common occurrence after coronary bypass surgery. J Am Coll Cardiol 1990; 15: 1261-9.

20 Seitelberger $R, Z$ wölfer $W$, Binder TM, et al. Infusion of nifedipine after coronary artery bypass grafting decreases the incidence of early postoperative myocardial ischaemia. Ann Thorac Surg 1990; 49: 61-8.

21 Bala Subramanian V, Lahira A, Green $H L$, Scott $F D$. Ambulatory ST-segment monitoring: problems, pitfalls, solutions and clinical application. Br Heart J 1980; 44: 419-25.

22 Slogoff S, Keats AS, David Y, Igo SR. Incidence of perioperative myocardial ischemia detected by different electrocardiographic systems. Anesthesiology 1990; 73: 1074-81.

23 Buxton AE, Goldberg S, Harken A, Hirshfield J Jr, Kastor JA. Coronary-artery spasm immediately after myocardial revascularization: recognition and management. N Engl J Med 1981; 304: 1249-53.

24 Forman MB, Puett $D W$, Virmani $R$. Endothelial and myocardial injury during ischaemia and reperfusion: pathogenesis and therapeutic implications. J Am Coll Cardiol 1989; 13; 450-9.

25 Ralley FE, Wynands JE, Ramsay JG, Garli F, MacSullivan $R$. The effects of shivering on oxygen consumption and carbon dioxide production in patients rewarming from hypothermic cardiopulmonary bypass. Can J Anaesth 1988; 35: 332-7.

26 Pratilas V, Pratila MG, Vlachakis ND, Owitz S, Dimich I. Sympathetic nervous system tonicity and post-coronary artery bypass hypertension. Acta Anaesthesiol Scand 1980; $24: 69-73$

27 Stanley $T H$, Berman $L_{4}$ Green $O$, Robertson D. Plasma cathecolamine and cortisol responses to fentanyl-oxygen anesthesia for coronary-artery operations. Anesthesiology $1980 ; 53: 250-3$
28 Airaksinen KEJ, Jkähemo MJ, Takkunen JT. Heart rate after coronary artery bypass grafting. Am J Cardiol 1987; 60: 1395-7.

29 Airaksinen KEJ, Ikäheimo MJ, Linnaluoto $M K$, Niemelä $M$, Takkunen $J T$. Impaired vagal heart rate control in coronary artery discase. Br Heart J 1987; 58: 592-7.

30 Schaff $H V$, Gersh BJ, Fisher $L D$, et al. Detrimental effect of perioperative myocardial infarction on late survival after coronary artery bypass: report from the Coronary Artery Surgery Study - CASS. J Thorac Cardiovasc Surg 1984; 88: 972-81. 